\title{
Automated urinalysis: First experiences and comparison of automated urinalysis system and manual microscopy
}

\author{
Gautam K ${ }^{1}$, Pyakurel D ${ }^{1}$ \\ ${ }^{I}$ Department of Pathology, Grande International Hospital, Dhapasi, Kathmandu, Nepal.
}

\section{Keywords: \\ Automated urinalysis; Urine microscopy; UF500i.}

\begin{abstract}
Background: Urinary tract infection is a common condition which needs laboratory evaluation of urine to substantiate the clinical diagnosis and initiate treatment. The conventional urinalysis consists of using a test strip for chemical examination to identify the various urine sediments after which visual microscopy is done. We evaluate the analytical performance of automated microscopic technique (UF 500i) and compare results with those from manual microscopy.
\end{abstract}

Materials and Methods: A total of 382 urine specimens were collected during a period of one month out of which 128 samples which had abnormal cell counts were analyzed for cells and particles by manual and automated microscopy by UF-500i flow cytometer.

Results: The concordance of UF 500i and the manual microscopy which is considered to be the gold standard for urine microscopic examination was $90.6 \%$ for white blood cells, red blood cell, epithelial cells, cast and bacterial count.

Conclusion: Automated urine sediment analyzer, UF 500i was considered reliable in the measurement of white blood cells, red blood cells, epithelial cells, cast and bacteria. Automation will surely reduce the work load, increase accuracy and reliability, and increase the throughput and turn-around time of the laboratory

\section{INTRODUCTION}

Urine microscopic examination is an essential screening procedure in laboratories for the detection of urinary tract infection. Urinary tract infection (UTI) is a term applied to a variety of clinical conditions, ranging from asymptomatic presence of bacteria in the urine to severe infection of the kidney with resultant sepsis. ${ }^{1}$ The conventional urinalysis

\section{Correspondence:}

Dr. Keyoor Gautam, MD

Head of Department, Department of Pathology and Laboratory Medicine, Grande International Hospital, Dhapasi, Kathmandu, Nepal.

E-mail:drkeyoor@gmail.com consists of using a test strip for chemical examination to identify the various urine sediments. Urine particle counting by visual microscopy is convenient, but is time consuming when examining a large number of samples. ${ }^{2}$ During the last 10 years, the use of flow cytometry based analyzers that measure quantitatively both leukocytes and bacteria has been evaluated. ${ }^{3}$ These methods have been shown to be as effective as the manual count at detecting urinary sediments. The aim of the study is to evaluate the analytical performance of automated microscopic technique (UF 500i, Sysmex, Japan) and compare results with those from manual microscopy. 
Table 1: A semi-quantitative range for various urinary sediments analyzed by manual microscopy

\begin{tabular}{lcccccccc}
\hline \multicolumn{1}{c}{ Parameters } & \multicolumn{7}{c}{ Semiquantative Ranges } \\
\hline WBC/HPF & $0-5$ & $6-10$ & $11-15$ & $16-20$ & $21-30$ & $31-50$ & $51-100$ & $>100$ \\
RBC/HPF & $0-5$ & $6-10$ & $11-15$ & $16-20$ & $21-30$ & $31-50$ & $51-100$ & $>100$ \\
EC/HPF & $0-5$ & $6-10$ & $11-15$ & $16-20$ & $21-30$ & $31-50$ & $51-100$ & $>100$ \\
Cast/LPF & Negative & & & & Positive & & \\
Bacteria/HPF & Negative & & Low & Moderate & High & Numerous
\end{tabular}

\section{MATERIALS AND METHODS}

Urine specimen submitted from the outpatient department to the Department of Pathology and Laboratory Medicine at Grande International Hospital, during a period of one month, from 1st January 2014 to 31st January 2014, for routine urinalysis was selected for the study. Out of 382 urine specimens 128 samples which had abnormal cell counts were analyzed for cells and particles by manual and automated microscopy. All samples were analyzed on the same day by trained technologists and the results were verified by the available consultant pathologist.

The UF500i is an automated urine microscopy analyzer that uses flow cytometry method to analyze elements contained in urine. The UF500i requires a volume of $800 \mu \mathrm{L}$ of urine out of which $150 \mu \mathrm{L}$ is used to measure sediments and $62.5 \mu \mathrm{L}$ to analyze the bacteria. For sediment analysis the urine is diluted in the chamber four times, together with $15 \mu \mathrm{L}$ of stain reagent, where as for bacteria analysis, it is diluted eight folds. Before running the samples, a negative and positive control samples were run according to the manufacturer's instructions. The results are displayed as scattergram, histogram and quantitatively. The parameters displayed were red blood cells (RBC), white blood cells (WBC), epithelial cells (EC), casts and bacteria.

The manual microscopy method was performed according to the work instructions and guidelines provided by the laboratory. Ten $\mathrm{ml}$ of urine was centrifuged at $2000 \mathrm{rpm}$ for five minutes, $9 \mathrm{ml}$ of supernatant discarded. After resuspension, $50 \mu \mathrm{L}$ of urine was pipette on to a glass slide, covered with a cover slip and examined under a light microscopy. The examination was done by estimation of the urine sediments in 10 fields, either in high power field (HPF) or in low power field (LPF), depending on the type of particle. A semi-quantitative range was fixed in order to compare the two methods as follows (Table 1). Concordance between the two methods was determined by statistically analysis.

\section{RESULTS}

Out of 382 patients whose urine was examined 128 sample had abnormal urinary sediment counts. Females were more commonly affected than males with a ration of 3.4:1.
Table 2: Accuracy of UF500i system in comparison with microscopic results

\begin{tabular}{cc}
\hline Parameters & Agreement (\%) UF 500i \\
WBC & 88 \\
RBC & 89 \\
EC & 94 \\
Cast & 92 \\
Bacteria & 90 \\
\hline
\end{tabular}

The concordance of UF500i and the gold standard microscopy was calculated for each semiquantative range and an average was taken (Table 2).

The concordance between UF 500i and the gold standard manual microscopy was on an average of $90.6 \%$ for the above five parameters.

\section{DISCUSSION}

Urine analysis for screening of infection and other diseases is of great value in clinical practice. Chemical analysis is first done which is followed by microscopic examination. Manual urine sediment analysis is considered labor intensive, time consuming, high inter observer variable and exhibits low reproducibility. ${ }^{4}$ Automated urine sediment analyzers are now available. In this study, the UF 500i performance demonstrated a good correlation with manual microscopy which is still considered the gold standard although it has various limitations.

The agreement in this study between the automated system (UF 500i) and microscopy was similar to other studies..$^{5-8}$ In comparison to the study done by Shayanfar et al., most of the parameters showed similar results except for bacteria which was only $42 \%$ in their study where as in ours it was $90 \% .{ }^{6}$ However, the correlation of the bacteria present with the gold standard method of culture was not performed in our study.

Screening for urine samples by flow cytometry has reduced the need for culture, significantly diminishing the amount of work required in the microbiology laboratory. ${ }^{9-11}$ Conventional microscopic analysis of urine sediments although considered to be the reference method, in values 


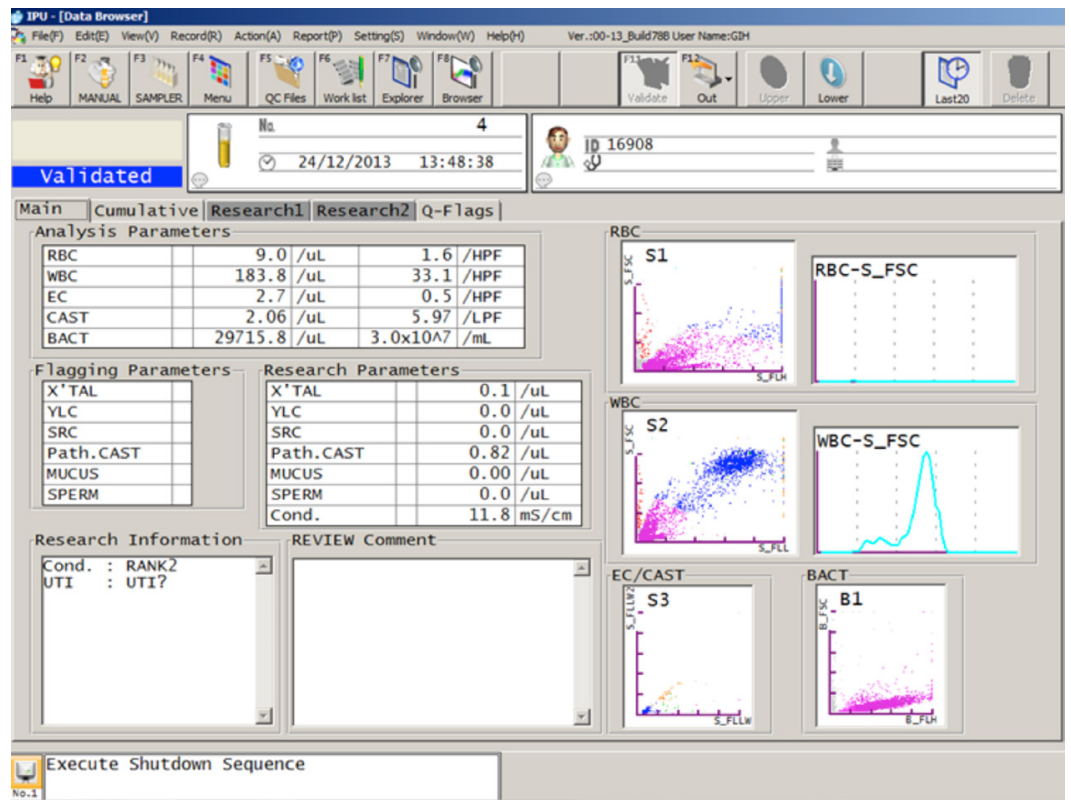

Figure 1: A view of the UF 500i window.

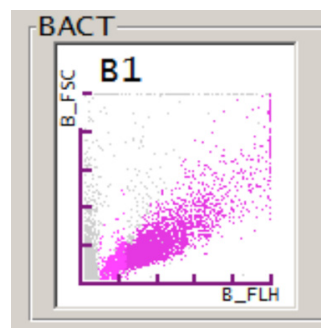

Figure 2: Slope of the bacteria cluster distributed along with diagonal line suggests coccus.

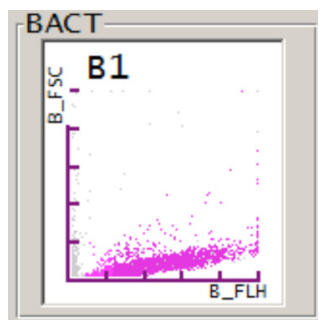

Figure 3: Slope of the bacteria cluster distributed in a narrow zone suggests rod. discarding that lead to loss and destruction of cells and result in imprecision and inaccuracy. ${ }^{6}$ These procedures are not required in the automated analysis. The turn-around time has markedly decreased and good reproducibility. The software used in UF 500i also provides us with a scattergram along with quantitative values for $\mathrm{RBC}, \mathrm{WBC}$, epithelial cells, cast, bacteria, crystals, yeast, pathological cast, mucus and sperm (fig. 1).

An important parameter demonstated is the bacterial orientation which provides tow kinds of typical slope:

-Slope 1: the slope of the bacteria cluster is made of data points distributed densely and broadly along the diagonal line. This possibly suggests that the bacterium in the urine is a coccus (fig. 2).

-Slope 2: the slope of the bacterial cluster is small and moreover the cluster is concentrated in a narrow zone. This possibly indicates that the bacterium in the urine is a rod (fig. 3). ${ }^{12}$

These scattergrams should be correlated with urine culture results. The clinicians will have a preliminary idea on the causative organism, hence helping them in the choice of antibiotic in treating patient with urinary tract infections.

According to the European urinalysis guidelines, the parameters that should be counted most accurately are $\mathrm{RBC}, \mathrm{WBC}$ and bacteria. ${ }^{13}$ A good correlation to the above parameters were observed in our study. However, some limitations were considered in this study. The sample size might be too small, bacteria was correlated only semiquantitatively and other urine sediment parameters such as crystals, yeast cells, mucus and sperm were not evaluated. Bacteria load and with culture positivity was also not correlated in our study.

\section{CONCLUSION}

Automated urine sediment analyzer, UF 500i was considered reliable in the measurement of $\mathrm{WBC}, \mathrm{RBC}, \mathrm{EC}$, cast and bacteria. Automation will surely reduce the work load, increase accuracy and reliability, and increase the throughput and turn-around time of the laboratory.

\section{REFERENCES}

1. Nguyen HT. Bacterial infections of the genitourinary tract. In: Tanagho EA, McAninch JW, editors. Smith's General Urology. 16th ed. Singapore: McGraw Hill;2004. p203.PMCid:PMC1664878

2. Szwed JJ, Schaust C. The importance of microscopic examination of the urinary sediment. Am J Med Technol 1982;48:141-3. PMid:7064990

3. Ben-Ezra J, Brok L, McPherson R. Evaluation of the Sysmex UF100 automated urinalysis analyzer. Clin. Chem 1998;44:92-5. PMid:9550564

4. Winkel P, Statland BE, Jorgensen K. Urine microscopy, an illdefined method, examined by a multifactorial technique. Clin. Chem 


\section{4;20:436-9.PMid:4818195}

5. Budak YU, Huysal K. Comparison of three automated systems for urine chemistry and sediment analysis in routine laboratory practice. Clin Lab 2011;57:47-52.PMid:21391464

6. Shayanfar N, Tobler U, Eckardstein AV, Bestmann L. Automated urinalysis: first experience and a comparison between the Iris iQ200 urine microscopy system, the Sysmex UF-100 flow cytometer and manual microscopic particle counting. Clin Chem Lab Med 2007;45:1251-6. CrossRef

7. Jintasuthanont $P$, Khejonnit V, Opaskiattikul N, Chinswangwatanakul W, Gonggetyai V. Evaluation of the Performance of the Automated Urine Sediment Analyzer "Urised" Compared with the Manual Method. Sirijaj Med J 2010;62:152-6. [Available at; URL: www. sirirajmedj.com/content_download.php?content_id=2536]

8. Gyory AZ, Hawkins T, Ross M, McLennan J, Ibels L. Clinical value of urine microscopy by manual and automated methods. Lab Hemat 1998;4:211-6.
9. Jolkkonen S, Paattiniemi EL, Karpanoja P, Sarkkinen H. Screening of Urine Samples by Flow Cytometry Reduces the Need for Culture. J Clin Microbiol 2010;48:3117-21. CrossRef

10. Hu X, Zhang J, Zhang X. Evaluation of the Sysmex UF-1000i Urine Analyzer as a Screening Test to Reduce the Need for Urine Cultures for Urinary Tract Infection. Lab medicine 2010;41:349-52. CrossRef

11. Broeren MAC, Bahceci S, Vader HL, Arents NLA. Screening for Urinary Tract Infection with the Sysmex UF-1000i Urine Flow Cytometer. J Clin Microbiol 2011;49:1025-9. CrossRef

12. Acedo JM, Delgado-Iribarren A, Artaza C, Morito M, Fernandez J, Valverde J. Evaluation of the UF1000i flow cytometer as a means of reducing urine cultures and predicting the microorganisms involved in urinary tract infections. Clin Microbiol Infect 2010;2:639.

13. Chien TI, Kao JT, Liu HL et al. Urine sediment examination: a comparison of automated urinalysis systems and manual microscopy. Clin Chim Acta 2007;384:28-34. CrossRef 